\title{
The Risk Factors of Puberty Precocious in Girls: Is the Condition Related with Polychlorobiphenyls?
}

\author{
(D) Raziye Burcu Güven Bilgin1, (1) Samim Özen², (1) Ruhsar Damla Gökşen², (1) Özlem Korkmaz², \\ (1) Şükran Darcan²
}

${ }^{1}$ Ege University Faculty of Medicine, Department of Pediatric Rheumatology, İzmir, Turkey

${ }^{2}$ Ege University Faculty of Medicine, Department of Pediatric Endocrinology, İzmir, Turkey

\begin{abstract}
Aim: Our aim was investigate the effect of polychlorobifenyls (PCBs) and other factors on puberty precocious (PP) in girls were diagnosed with idiopatic PP and premature thelarche (PT).

Materials and Methods: The study group included 50 girls aged between 2-8 years old with PP and PT. The control group included 50 healthy girls with same age range and no puberty findings. Data was collected in terms of breast and pubic hair stages, weight, height, body mass index (BMI), standard deviation scores (SDSs), location of residence, gestational age and maternal age at menarche (AAM). Twenty-one PCB levels were evaluated in serum and urine. One-Way ANOVA test was used for comparison between the groups. For subgroup analysis, Mann-Whitney $\mathrm{U}$ test, multiple regression analysis were used.

Results: The mean age of the study and control groups were $6.70 \pm 1.20$ and $5.23 \pm 1.25$ years, respectively. The studied PCBs were not detectable found in either the study or the control groups. The BMI SDSs of the patients in study and healthy groups were $0.49 \pm 1.09$ and $-0.12 \pm 1.28$, respectively $(p=0.1)$. Weight SDSs in the study group were found to be significantly higher than healthy group $(0.72 \pm 1.35 \mathrm{vs}-0.20 \pm 1.47, p=0.008$ Maternal AAM of the patients in study group was significantly lower $(p=0.006)$. In study group $98 \%$ of the patients were living in down town and district, whereas this ratio was $92 \%$ in control group $(p=0.024)$. In study group 29 patients $(58 \%)$ were diagnosed with PT. Basal follicle stimulating hormone and estradiol levels, bone age and uterine longest axis dimensions results were significantly different.

Conclusion: We found that studied PCBs don't influence on PP in girls aged between 2-8 years old. However, weight SDS, maternal AAM, location of residence of the patients had a significant role on PP in this patient population.
\end{abstract}

Keywords: Puberty precocious, premature thelarche, environmental endocrine distrubs, polychlorobifenyl, obesity

\section{Introduction}

Over the last century, it has been seen that the age of onset of puberty has tended to shift earlier. Sorensen et al. (1) have argued that the age of onset of breast development in America has shifted earlier. Central precocious puberty (CPP) occurs as a result of the early activation of the hypothalamus-pituitary-gonad axis and is characterized by the development of secondary sex characteristics in girls before the age of eight (2). Although it is thought that there are many reasons for this, genetic factors, nutritional differences, ethnic origin, environmental factors, and exposure to endocrine disruptors are among the common causes $(3,4)$.

Endocrine disruptors, being one of the causes of CPP, can alter the production, transport, destruction and excretion

*Poster Presentation: 57 ${ }^{\text {th }}$ Annual ESPE 2018 Meeting 27-29 September in Athens, Greece (335-P2). 
of endogenous hormones and even alter their effects on the target cell. One or more of these effects may also occur together. Exposure can occur transplactentally during the prenatal period, with breast milk in infancy, through inhalation and digestion in childhood, or due to industrial accidents (5). Polychlorinated biphenyls (PCBs), being one of these chemicals, are theoretically constituted of 209 different types of chemical and aromatic compounds that are formed by binding different numbers of chlorine ions in different configurations on a biphenyl structure. They can also be found in synthetic and industrial products. PCBs have been used as organic diluents, softeners, pesticide extenders, adhesives, dust reducers, cutting oils, flame retardants, heat transfer fluids, dielectric fluids for transformers and capacitors, hydraulic lubricants, sealants and in carbonless copy paper. A significant portion of the environmental burden of these compounds is due to careless disposal practices, accidents, leakage from various industrial plants, and chemical waste disposal sites (6). Most of these compounds are lipophilic and have a long half-life. As a result, they accumulate in adipose tissue in living creatures and long-term exposure, even at low levels, may cause chronic toxicity (7). As humans rank high in the food chain at the trophic level, they accumulate high concentrations of these pollutants in lipid tissues and may become more vulnerable to their toxic effects (8).

The main purpose of this study was to analyse the effect of twenty PCB groups, namely; PCB 8, PCB 20, PCB 28, PCB 35, PCB 52, PCB 77, PCB 81, PCB 101, PCB 105, PCB 114, PCB 118, PCB 123, PCB 126, PCB 138, PCB 153, PCB 156, PCB 157, PCB 167, PCB 169 and PCB 189 on PP in girls with the diagnosis of PP or premature thelarche (PT) in our Paediatric Endocrinology Outpatient Clinic. Furthermore, the relationship between PP and the other possible factors such as weight, height, body mass index (BMI), gestational age at birth and maternal age at menarche (AAM) and the residence location of the patients were investigated.

\section{Materials and Methods}

The study was conducted after approval was given by the Ethics committee of Ege University Faculty of Medicine (date: 29.12.2015, approval no: 15-11/4).

The study group (group 1) included 50 girls aged between 2 and 8 years old with a diagnosis of idiopathic PP or isolated PT in a single Paediatric Endocrinology Outpatient Clinic. The control group (group 2) included 50 healthy girls with the same age range in the same centre who were admitted to the same department for their routine check-ups and had previously had no chronic disease or evidence of puberty signs.
In the investigation of patients with precocious puberty, their anthropometric measurements and clinicodemographic characteristics were evaluated, and the Tanner stages of the patients were identified. Serum and urine samples were obtained from each patient in order to determine PCB levels. Bone age (BA) (according to the Greulich-Pyle BA atlas), ovarian and uterus sizes, morning basal luteinizing hormone (LH), follicle stimulating hormone (FSH), and estradiol (E2) serum levels were recorded from the files of the patients in group 1. In pelvic ultrasonographic imaging of the patients, cases with ovaries whose longest axis was $2.5 \mathrm{~cm}$ or $1 \mathrm{~cm}^{3}$ in volume from the ovarian dimensions were accepted as being in adolescence, cases with a long axis exceeding $3.4 \mathrm{~cm}$ from the uterine dimensions or with an endometrial echo exceeding $2 \mathrm{~mm}$ were accepted as being in adolescence (9). Basal FSH, LH, E2 levels were measured in the serum sample by electrochemiluminescence immunoassay method using Roche Diagnostic $\mathrm{GmbH}$ (Germany) kits in a Modular Analytics E170- Roche Diagnostic $\mathrm{GmbH}$ (Germany) device. In these kits, measurement ranges are given as 0.01-200 $\mathrm{mlU} / \mathrm{mL}$ for $\mathrm{LH}$ and $\mathrm{FSH}$ and 5.0-4,300 $\mathrm{pg} / \mathrm{mL}$ for E2. Basal LH values $>0.6 \mathrm{mIU} / \mathrm{mL}$ were accepted as true PP. Basal E2 levels above $12 \mathrm{pg} / \mathrm{mL}$ were considered higher than the age group (10). Those patients with isolated PT had glandular breast tissue on palpation (as opposed to lipomastia). Their BA corresponded with their chronological age, basal and $\mathrm{GnRH}$-stimulated gonadotropin levels were normal and other signs of puberty such as pubarche and menarche were absent in contrast to those patients with precocious puberty.

Both groups were assessed based on the patients gestational ages, and location of residence. Preterm birth was determined as being born before the $37^{\text {th }}$ week, and term-birth was determined as having a birth age between 37 and 40 weeks. The location of residence was classified as urban or rural. Maternal AAM, mean BMI and mean weight standard deviation scores (SDSs) of the groups were also compared.

Serum and urine samples of all patients included in the study were stored at $-80^{\circ} \mathrm{C}$ until they were analysed. Serum and urine PCB measurements were made at Ege University Drug Development and Pharmacokinetics Research Application Centre. For PCB analysis, serum samples were studied by the gas chromatography mass spectrometry (GC-MS) method on a Shimadzu GC-MS QP-2010 Plus (Japan) device. Restek CL Pesticides 2 (20 m, 0.18 mm i.d. $014 \mu \mathrm{m}$ film thickness) was used as the column. The column temperature was initially increased from $120^{\circ} \mathrm{C}$ to $200{ }^{\circ} \mathrm{C}$ at a rate of $45^{\circ} \mathrm{C} / \mathrm{min}$. Then it was increased to $230^{\circ} \mathrm{C}$ at a 
rate of $15^{\circ} \mathrm{C} /$ minute, and finally to $300^{\circ} \mathrm{C}$ at a rate of $30^{\circ} \mathrm{C} /$ minute and then kept constant for 3 minutes. For the study, $1 \mathrm{~mL}$ of serum was put into a glass tube and $9 \mathrm{~mL}$ of type 1 water was added. Solid-phase extraction (SPE) cartridges were lined up in the manifold. Five $\mathrm{mL}$ of methanol, $5 \mathrm{~mL}$ of methyl-tert-butyl ether (MTBE) and $3 \mathrm{~mL}$ of type 1 water were passed through the cartridge, respectively. The serum sample was then loaded into the SPE cartridge. The sample flow rate was set at $6-8 \mathrm{~mL} /$ minute. After passing the sample, the cartridge was washed with $3 \mathrm{~mL}$ of type 1 water and dried under vacuum for 10-15 minutes. The extract collected at the bottom was discarded and a clean glass tube was placed in the manifold. Collection was done with $5 \mathrm{~mL}$ MTBE. After the collected extract was evaporated to dryness under nitrogen at $40{ }^{\circ} \mathrm{C}$ bath temperature, $1 \mathrm{~mL}$ $\mathrm{n}$-Hexane was added to the tube and mixed by vortex. It was filtered through $0.45 \mathrm{~m}$ polytetrafluoroethylene filter and put into a vial and injected into the GC-MS system.

Using the Quechers kit for PCB analysis in urine samples; 5-10 $\mathrm{g}$ of the sample was weighed. It was put into a 50 $\mathrm{mL}$ Teflon tube. Ten $\mathrm{mL}$ of $1 \%$ acidified acetonitrile (with acetic acid), containing $100 \mathrm{ng} / \mathrm{g}$ Aldrin standard (internal standard) was added to the sample. The mouth of the tube was tightly closed and shaken by hand for about 1 minute. Ready mix containing $6 \mathrm{~g}$ magnesium sulphate (MgSO4) and $1.5 \mathrm{~g}$ sodium acetate $(\mathrm{CH} 3 \mathrm{COONa})$ was added to the sample. The mouth of the tube was tightly closed and shaken by hand for about 1 minute. It was then mixed by high-speed vortex for 5 minutes. It was centrifuged for 5 minutes at 4,000 rpm. Liquid Extract was transferred to a 10 $\mathrm{mL}$ ready-made tube containing 2-8 $\mathrm{mL}$ of $400 \mathrm{mg}$ primary secondary amine and 1,200 $\mathrm{mg}$ of $\mathrm{MgSO}$. The mouth of the tube was tightly closed and shaken by hand for about 1 minute. It was then mixed by high-speed vortex for 5 minutes. It was centrifuged at 4,000 rpm for 5 minutes. It was filtered from the upper phase to the vial and delivered to GC ECD/GCMS devices.

The studied $P C B$ s in laboratory tests were as follows: PCB 8, PCB 20, PCB 28, PCB 35, PCB 52, PCB 77, PCB 81, PCB 101, PCB 105, PCB 114, PCB 118, PCB 123, PCB 126, PCB 138, PCB 153, PCB 156, PCB 157, PCB 167, PCB 169 and PCB 189. The qualitative and quantitative results were evaluated. For quantitative measurements, any PCB levels higher than $0.005 \mathrm{mg} / \mathrm{kg}$ were noted.

\section{Statistical Analysis}

The statistical analyses were performed using SPSS version 16.0. The One-Way ANOVA test was used for comparisons between groups. For subgroup analysis, Mann-
Whitney $\mathrm{U}$ test and multiple regression analysis were used. A p-value $<0.05$ was accepted as statistically significant.

\section{Results}

In group $1(n=50)$, the mean age was $6.7 \pm 1.2$ years. In group $2(n=50)$, the mean age was $5.23 \pm 1.25$ years. When the anthropometric measurements were compared, the weight SDS in group 1 was $0.72 \pm 1.35$, the height SDS was $0.77 \pm 1.40$, the BMI SDS was $0.49 \pm 1.09$. In group 2, the weight SDS was $-0.20 \pm 1.47$, the height SDS was $-0.35 \pm 1.54$, and the BMI SDS was found to be $-0.12 \pm 1.28$. While there was no difference between group 1 and group 2 in terms of height and BMI SDS, the weight SDS in group 2 were found to be significantly higher than group $1(p<0.05)$ (Table I).

When the relationship between the time of birth (preterm or term) and the onset of puberty was evaluated, it was observed that the rate of delivery on time was $88 \%$ in group 1 and $84 \%$ in the healthy control group. It was observed that the preterm birth rate was $12 \%$ in group 1 and $16 \%$ in the healthy control group. There was no statistically significant difference in delivery time between children entering early puberty and those in the healthy control group ( $p>0.05)$.

Maternal AAM (years) were $12.06 \pm 1.25$ in group 1 and $12.65 \pm 0.92$ in group $2(p=0.006)$. It was determined that the age of onset of maternal menarche was statistically significantly earlier in group 1 than in group $2(p<0.05)$ (Table II).

When the relationship between professions of the

\begin{tabular}{|l|l|l|l|}
\hline \multicolumn{4}{|l|}{ Table I. Anthropometric measurements of the groups } \\
\hline & $\begin{array}{l}\text { Study group } \\
(\mathbf{n}=\mathbf{5 0 )}\end{array}$ & $\begin{array}{l}\text { Control group } \\
\mathbf{( n = 5 0 )}\end{array}$ & $\mathbf{p}$-value \\
\hline Weight SDS & $0.72 \pm 1.35$ & $-0.20 \pm 1.47$ & $\mathbf{0 . 0 0 8}$ \\
\hline Height SDS & $0.77 \pm 1.40$ & $-0.35 \pm 1.54$ & 0.12 \\
\hline BMI SDS & $0.49 \pm 1.09$ & $-0.12 \pm 1.28$ & 0.1 \\
\hline \multicolumn{4}{|l|}{ BMI: Body mass index, SDS: Standard deviation score } \\
\hline
\end{tabular}

Table II. The relationship between puberty precocious, premature thelarche and gestational age at birth and maternal menarche age

\begin{tabular}{|l|l|l|l|}
\hline & $\begin{array}{l}\text { Study group } \\
(\mathbf{n}=\mathbf{5 0 )}\end{array}$ & $\begin{array}{l}\text { Control group } \\
(\mathbf{n = 5 0 )}\end{array}$ & p-value \\
\hline $\begin{array}{l}\text { Maternal } \\
\text { menarche age }\end{array}$ & $12.06 \pm 1.25$ & $12.65 \pm 0.92$ & 0.006 \\
\hline $\begin{array}{l}\text { Premature born } \\
(\%)\end{array}$ & 12 & 16 & \\
\hline Term born (\%) & 88 & 84 & 0.56 \\
\hline
\end{tabular}


mothers and fathers of both groups and the time of onset of puberty was examined, it was seen that $58 \%$ of the mothers in group 1 were housewives, 24\% were self-employed and $18 \%$ were civil servants, $66 \%$ of fathers were self-employed and $34 \%$ were civil servants. In group $2,74 \%$ of the mothers were housewives, $14 \%$ were self-employed, $12 \%$ were civil servants, and $2 \%$ of fathers were unemployed, $78 \%$ were self-employed and $20 \%$ were civil servants. No statistically significant difference was found between family professions and the onset of puberty ( $p>0.05)$.

When birth weights were examined, the mean birth weight of group 1 was 3,180 gr \pm 664 and the mean birth weight of group 2 was $3,048 \mathrm{gr} \pm 641$. There was no significant difference between group 1 and group 2 in terms of birth weight $(p=0.748)$.

The distribution of pubic hair growth and breast development stages according to Tanner at the time of admission in the girls were determined such that, in group $1,28 \%$ of patients ( $n=14$ ) were in pubarche stage $2,60 \%$ of patients $(n=30)$ were in pubarche stage $3,10 \%$ of patients $(n=5)$ were in pubarche stage 4 , and $2 \%$ of patients $(n=1)$ were in pubarche stage $5.8 \%(n=4)$ were in thelarche stage $2,64 \%$ of patients $(n=32)$ were in thelarche stage $3,20 \%$ of patients $(n=10)$ were in thelarche stage 4 , and $8 \%$ of patients $(n=4)$ were in thelarche stage 5 . At the time of application, delta BA of these patients was determined to be 0 in 22\% ( $n=11)$ of patients, 1 in 32\% ( $n=16)$ of patients, 1.5 in $16 \%(n=89)$ of patients, 2 in $28 \%(n=13)$ of patients, 3 in $2 \%(n=1)$ of patients, and 4 in $2 \%(n=1)$ of patients.

\section{CPP and Isolated PT Subgroups Results}

Twenty-nine out of 50 patients (58\%) in Group 1 were diagnosed with isolated PT, and 21 patients (42\%) were diagnosed with CPP. Anthropometric measurements were compared, the weight mean SDS in the CPP group was $0.89 \pm 1.43$, height SDS was $0.88 \pm 1.47$, and BMI SDS was $0.71 \pm 1.05$. In isolated PT, weight SDS was $-0.49 \pm 1.22$, height SDS was $0.63 \pm 1.31$, and BMI SDS was found to be $0.19 \pm 1.10$. There was no difference between the PP group and PT group. ( $p>0.05)$ (Table III).

Maternal AAM (years) were $11.9 \pm 1.2$ in the PP group and $12.2 \pm 1.3$ in the PT group ( $p=0.076)$. It was determined that maternal AAM was not statistically significantly ( $p>0.05)$.

The laboratory tests for differentiating precocious puberty from PT are BA, basal LH, FSH, E2 levels, pelvic ultrasonographic imaging of the ovaries and uterine longest axis and volume dimensions. BA was $1.48 \pm 0.83$ in the CPP group and $0.85 \pm 0.77$ in the isolated PT group $(p=0.015)$.

\begin{tabular}{|l|l|l|l|}
\hline \multicolumn{4}{|l|}{$\begin{array}{l}\text { Table III. Anthropometric measurements and laboratory values } \\
\text { of CPP and isolated PT patients' }\end{array}$} \\
\hline & $\begin{array}{l}\text { CPP group } \\
\text { (n=21) }\end{array}$ & $\begin{array}{l}\text { Isolated PT } \\
\text { group } \\
\text { (n=29) }\end{array}$ & p-value \\
\hline Weight SDS & $0.89 \pm 1.43$ & $0.49 \pm 1.22$ & 0.29 \\
\hline Height SDS & $0.88 \pm 1.47$ & $0.63 \pm 1.31$ & 0.53 \\
\hline BMI SDS & $0.71 \pm 1.05$ & $0.19 \pm 1.10$ & 0.97 \\
\hline Basal LH (mIU/mL) & $1.01 \pm 1.38$ & $0.53 \pm 0.78$ & 0.10 \\
\hline $\begin{array}{l}\text { Basal FSH (mIU/ } \\
\text { mL) }\end{array}$ & $3.53 \pm 1.88$ & $2.42 \pm 1.74$ & $\mathbf{0 . 0 1 6}$ \\
\hline Basal E2 (pg/mL) & $18.4 \pm 14.4$ & $8.76 \pm 18.4$ & $\mathbf{0 . 0 0}$ \\
\hline $\begin{array}{l}\text { Uterine longest } \\
\text { axis (mm) }\end{array}$ & $36.9 \pm 8.28$ & $29.8 \pm 10.4$ & $\mathbf{0 . 0 0 6}$ \\
\hline $\begin{array}{l}\text { Right ovarian } \\
\text { longest axis (mm) }\end{array}$ & $25.2 \pm 8.3$ & $24.2 \pm 8.7$ & 0.45 \\
\hline $\begin{array}{l}\text { Volume of } \\
\text { right ovary (cm }{ }^{3} \text { ) }\end{array}$ & $4.18 \pm 4.7$ & $4.85 \pm 6.9$ & 0.52 \\
\hline $\begin{array}{l}\text { Left ovarian } \\
\text { longest axis (mm) }\end{array}$ & $24.0 \pm 7.1$ & $20.6 \pm 6.47$ & 0.14 \\
\hline $\begin{array}{l}\text { Volume of } \\
\text { left ovary (cm }{ }^{3} \text { ) }\end{array}$ & $3.03 \pm 3.3$ & $2.47 \pm 2.2$ & 0.52 \\
\hline BA & $1.48 \pm 0.83$ & $0.85 \pm 0.77$ & $\mathbf{0 . 0 1 5}$ \\
\hline $\begin{array}{l}\text { BA: Bone age, BMI: Body mass index, CPP: Central puberty precocious, E2: } \\
\text { Estradiol, FSH: Follicule stimulating hormone, LH: Luteinizing hormone, PT: } \\
\text { Prematury telarche, SDS: Standard deviation score }\end{array}$ \\
\hline
\end{tabular}

This result is statistically significantly $(p<0.05)$. Uterine longest axis was $36.9 \pm 8.28$ in the CPP group and $29.8 \pm 10.4$ in the isolated PT group. Basal FSH ( $\mathrm{mlU} / \mathrm{mL})$ in the CPP group was $3.53 \pm 1.88$ and $2.42 \pm 1.74$ in the isolated PT group $(p=0.016)$. Basal E2 $(\mathrm{pg} / \mathrm{mL})$ in the CPP group was $18.4 \pm 14.4$ and $8.76 \pm 18.4$ in the isolated PT group $(p=0.00)$. The CPP and the isolated PT subgroups basal FSH, E2 levels, BA and uterine longest axis dimensions results were statistically significantly (Table III).

We were unable to demonstrate any quantifiable levels of PCB remnants in the serum and urine samples of the patients in either group.

\section{Discussion}

Our results demonstrated that the patient's location of residence, maternal $A A M$ and their weight had a significant role on PP in those girls aged between 2 and 8 years old. However, we were unable to demonstrate an association between PP and PCBs we studied or any other factors.

As far as we know, in the studies conducted so far, no relationship has been found between PCB exposure and 
early puberty in girls. In one study conducted to evaluate intrauterine $P C B$ exposure, they found no relationship between 6 PCB congeners $(118,138,153,156,170,180)$ and menarche age and menstrual cycle length in 436 Danish girls at an average age of 19.6. They also demonstrated 14\% shorter menstrual cycle times in girls exposed to high doses of 2 PCB congeners in comparison to those exposed to low doses (11). In another study conducted with 192 healthy 9-year-old girls living in New York, Wolff et al. (12) argued that PCB exposure had no effect on breast development and that breast development could be delayed in the group with high PCB exposure and low BMI. In another study, Su et al. (13) reported significantly lower E2 concentrations in eightyear-old children exposed to high levels of Polychlorinated Dibenzo-p-Dioxins and Polychlorinated Dibenzofurans (PCDD/Fs) and PCBs. Moreover, they demonstrated a significant association between $\mathrm{PCBs}$ median exposure level and fundus length after adjusting for BA. They concluded that in utero exposure to $\mathrm{PCBs}$ resulted in decreased serum E2 concentrations and this was thought to delay the reproductive development of these girls. They also observed a borderline significant effect of exposure level on breast and Tanner stages and found that there was a significant relationship between PCBs median exposure level and fundus length after adjusting for BA (13). Gellert (14) demonstrated that the estrogenic activity of a PCB was associated with decreased neuroendocrine differentiation and premature reproductive aging. Denham (15) showed that prepubertal PCB exposure caused menarche age to occur earlier in girls. In contrast, Vasiliu et al. (16) and Yang et al. (17) showed that PCB exposure in the prenatal and early postnatal period did not affect the age of menarche and pubertal development in girls.

In our study, no PCB residue was found in either group. Therefore, the relationship between PCB exposure and early puberty was not evaluated. The insufficient number of patients can be shown primarily among the reasons for not being able to determine a relationship between precocious puberty and PCB exposure. However, although PCB exposure has an effect on the early onset of puberty, the amount of PCBs may have been reduced to immeasurable levels due to the cross-sectional nature of the study. The individuals in the study group live in and around Izmir. The fact that the industrial establishments in this region have relatively less effect on the formation of PCBs can be considered as another reason why PCBs were not found in the serum samples of the patients. In addition, another limitation of this study is whether the individuals' living spaces were in industrial areas or not. It is thought that meaningful results may be found if they lived in industrial areas which could lead to PCB contamination.
In our study, the weight SDS of the group with early adolescence was found to be significantly higher. However, there was no significant difference between BMI. In the past decades, obesity has become a major health problem in childhood. Obesity can also cause a number of short-term and long-term metabolic disorders including cardiovascular diseases. In addition, it can affect the onset of puberty (18). Several studies have demonstrated that an earlier onset of puberty is associated with obesity in girls. It is known that a certain amount of body fat is a necessity for normal reproductive function. However, increased adipose tissue is a risk factor for pubertal disorders $(19,20)$. Early maturation nearly doubled the odds of being overweight in girls participating in the US National Longitudinal Study of Adolescent Health (21). Slora et al. (22) reported that $\mathrm{BMI}$ is significantly associated with the onset of puberty since heavier children reach puberty earlier. Two of the mechanisms suggested to explain the relationship between $\mathrm{BMI}$ increase and precocious puberty are high leptin levels and insulin resistance mechanisms. Leptin is a hormone that originates in the adipose tissue and it is essential for normal puberty development. In studies, low leptin levels and delayed puberty were found in girls with less than normal adipose tissue (23). In a study conducted by Matkovic $V$ et al. (24) regarding leptin levels above $12 \mathrm{ng} /$ $\mathrm{mL}$, it was found that every $1 \mathrm{ng} / \mathrm{mL}$ increase in leptin level shifts the age of menarche 1 month earlier. However, leptin and insulin levels were not studied in our study.

In the current study, there was an association between PP and maternal AAM and the location of patient's residence. The mean age of maternal menarche was significantly lower in those patients with PP. In concordance, Durand et al. (25) confirmed the high incidence of affected girls with familial early puberty. The mode of inheritance of the phenotype was predominantly maternal. Furthermore, they found that the maternal AAM of the girls with the familial form of CPP was significantly lower than in those with sporadic forms. In addition, we found that those girls living in urban areas carried a significantly higher risk of PP. Similarly, in a study by Ma et al. (26), it was noted that urban Chinese girls were experiencing earlier breast development than the current norm.

\section{Study Limitations}

Our study has some limitations. First of all, the size of the study population was low. The second limitation was that it only consisted of patients from a limited area, and therefore did not reflect a wide geographic region. In addition, we could only investigate 20 PBCs. These might explain why we could not detect any of the PCBs in the samples of our patients. 


\section{Conclusion}

In conclusion, we demonstrated that PCBs we studied do not have an influence on PP in girls aged between 2 and 8 years old. However, living in an urban area, having a higher weight and a lower age of maternal menarche had a positive effect on PP in girls aged between 2 and 8 years old. In order for the endocrine disruptors to show their effects, the time, length and amount of exposure are important. We can conclude that exposure to PCBs in our region is not enough to have any effects on puberty.

\section{Ethics}

Ethics Committee Approval: The study was conducted after approval of the Ethics comittee of Ege University Faculty of Medicine (approval date: 29.12.2015; approval no: 15-11/4).

Informed Consent: Retrospective study.

Peer-review: Externally peer-reviewed.

\section{Authorship Contributions}

Design: Ş.D., Data Collection or Processing: R.B.G.B., S.Ö., Ö.K., Ş.D., Writing: R.B.G.B., R.D.G.

Conflict of Interest: No conflict of interest was declared by the authors.

Financial Disclosure: The authors declared that this study received no financial support.

\section{References}

1. Sorensen K, Aksglaede L, Juul A, Petersen JH, Skakkebaek NE. Recent decline in age at breast development: the copenhagen puberty study. Pediatrics 2009; 12:e932-9. doi: 10.1542/ peds.2008-2491.

2. Carel JC, Leger J. Precocious puberty. N Eng J Med 2008; 358:236677.

3. Teilmann G, Skakkebaek NE, Parent AS, Toppari J, Bourguignon IP, Juul A. The timing of normal puberty and the age limits of sexual precocity: variations around the world, secular trends, and changes after migration. Endocr Rev 2003; 24:668-93.

4. Sørensen K, Mouritsen A, Aksglaede L, Hagen CP, Mogensen SS, Juul A. Recent secular trends in pubertal timing: Implications for evaluation and diagnosis of precocious puberty. Horm Res Paediatr 2012; 77:137-45.

5. Teilmann G, Juul A, Skakkebæk NE, Toppari J. Putative effects of endocrine disrupters on pubertal development in the human. Best Pract Res Clin Endocrinol Metab 2002; 16:105-21.

6. Safe SH. Polychlorinated biphenyls (PCBs): Environmental impact, biochemical and toxic responses, and implications for risk assessment. Crit Rev Toxicol 1994; 24:87-149.

7. Dich J, Zahm SH, Hanberg A, Adami HO. Pesticides and cancer. Cancer Causes Control 1997; 8:420-43.

8. Cherif D, Driss MR, Tebourbi O, et al. Organochlorine pesticides and polychlorinated biphenyls in human adipose tissue from northern Tunisia: Current extent of contamination and contributions of socio-demographic characteristics and dietary habits. Environ Res 2017; 156:635-43.

9. Lee PA, Wilson DM, Hintz RL, Neely EK, Stene M. Spontaneous serum gonadotropin concentrations in the evaluation of precocious puberty. I Pediatr 2005; 127:47-52.

10. Brito VN, Batista MC, Borges MF, et al. Diagnostic value of fluorometric assays in the evaluation of precocious puberty. I Clin Endocrinol Metab 1999; 84:3539-44.

11. Kristensen SL, Ramlau-Hansen $\mathrm{CH}$, Ernst E, et al. Prenatal exposure to persistent organochlorine pollutants and female reproductive function in young adulthood. Environ Int 2016; 92-93:366-72.

12. Wolff MS, Britton JA, Boguski L, et al. Environmental exposures and puberty in inner-city girls. Environ Res 2008; 107:393-400.

13. Su PH, Huang PC, Lin CY, Ying TH, Chen JY, Wang SL. The effect of in utero exposure to dioxins and polychlorinated biphenyls on reproductive development in eight year-old children. Environ Int 2012; 39:181-7.

14. Gellert RJ. Uterotrophic activity of polychlorinated biphenyls $(P C B)$ and induction of precocious reproductive aging in neonatally treated female rats. Environ Res 1978; 16:123-30.

15. Denham M. Relationship of lead, mercury, mirex, dichlorodiphenyldichloroethylene, hexachlorobenzene, and polychlorinated biphenyls to timing of menarche among Akwesasne Mohawk girls. Pediatrics 2005; 115:e127-34. doi: 10.1542/peds.2004-1161.

16. Vasiliu O, Muttineni J, Karmaus W. In utero exposure to organochlorines and age at menarche. Hum Reprod 2004; 19:1506-12.

17. Yang CY, Yu ML, Guo HR, et al. The endocrine and reproductive function of the female Yucheng adolescents prenatally exposed to PCBs/PCDFs. Chemosphere 2005; 61:355-60.

18. Lobstein T, Baur L, Uauy R. Obesity in children and young people : a crisis in. Obes Rev 2004; 5:4-85

19. Burt Solorzano CM, McCartney CR. Obesity and the pubertal transition in girls and boys. Reproduction 2010; 140:399-410.

20. Prété G, Couto-Silva AC, Trivin C, Brauner R. Idiopathic central precocious puberty in girls: Presentation factors. BMC Pediatr 2008; 8:1-8.

21. Adair LS, Gordon-Larsen P. Maturational timing and overweight prevalence in US adolescent girls. Am J Public Heal 2001; 91:6424.

22. Slora EJ, Pedlow SE, Wasserman RC, Kaplowitz PB, HermanGiddens ME. Earlier Onset of Puberty in Girls: Relation to Increased Body Mass Index and Race. Pediatrics 2004; 108:34753

23. Chan JL, Mantzoros CS. Leptin and the hypothalamic-pituitary regulation of the gonadotropin-gonadal axis. Pituitary 2001; 4:87-92.

24. Matkovic V, Ilic JC, Skugor M, et al. Leptin Is Inversely Related to Age at Menarche in Human Females. I Clin Endocrinol Metab 1997; 82:3239-45.

25. Durand A, Bashamboo A, McElreavey K, Brauner R. Familial early puberty: Presentation and inheritance pattern in 139 families. BMC Endocr Disord 2016; 16:50.

26. Ma HM, Du ML, Luo XP, et al. Onset of breast and pubic hair development and menses in urban chinese Girls. Pediatrics 2009; 124:e269-77. doi: 10.1542/peds.2008-2638. 